\title{
Characteristics of a persistent "pool of inhibited cloudiness" and its genesis over the Bay of Bengal associated with the Asian summer monsoon
}

\author{
Anish Kumar M. Nair, K. Rajeev, S. Sijikumar, and S. Meenu \\ Space Physics Laboratory, Vikram Sarabhai Space Centre, Thiruvananthapuram 695 022, India \\ Received: 25 February 2011 - Revised: 2 June 2011 - Accepted: 20 June 2011 - Published: 13 July 2011
}

\begin{abstract}
Using spatial and vertical distributions of clouds derived from multi-year spaceborne observations, this paper presents the characteristics of a significant "pool of inhibited cloudiness" covering an area of $>10^{6} \mathrm{~km}^{2}$ between $3-13^{\circ} \mathrm{N}$ and $77-90^{\circ}$ E over the Bay of Bengal (BoB), persisting throughout the Asian summer monsoon season (ASM). Seasonal mean precipitation rate over the "pool" is $<3 \mathrm{~mm} \mathrm{day}^{-1}$ while that over the surrounding regions is mostly in the range of 6-14 mm day ${ }^{-1}$. Frequency of occurrence of clouds in this "pool" is $\sim 20-40 \%$ less than that over the surrounding deep convective regions. Zonal and meridional cross sections of the altitude distribution of clouds derived from CloudSat data reveal a vault-like structure at the "pool" with little cloudiness below $\sim 7 \mathrm{~km}$, indicating that this "pool" is almost fully contributed by the substantially reduced or near-absence of low- and middle-level clouds. This suggest the absence of convection in the "pool" region. Spaceborne scatterometer observations show divergence of surface wind at the "pool" and convergence at its surroundings, suggesting the existence of a mini-circulation embedded in the large-scale monsoon circulation. Reanalysis data shows a mini-circulation extending between the surface and $\sim 3 \mathrm{~km}$ altitude, but its spatial structure does not match well with that inferred from the above observations. Sea surface at the south BoB during ASM is sufficiently warm to trigger convection, but is inhibited by the subsidence associated with the mini-circulation, resulting in the "pool". This minicirculation might be a dynamical response of the atmosphere to the substantial spatial gradient of latent heating by largescale cloudiness and precipitation at the vast and geographically fixed convective zones surrounding the "pool". Subsidence at the "pool" might contribute to the maintenance of convection at the above zones and be an important component of ASM that is overlooked hitherto.
\end{abstract}

Correspondence to: K. Rajeev

(k_rajeev@vssc.gov.in)
Keywords. Atmospheric composition and structure (Cloud physics and chemistry) - Meteorology and atmospheric dynamics (Climatology; Tropical meteorology)

\section{Introduction}

Spaceborne observations and experimental campaigns during the past few decades have made significant advancements in the understanding of the Asian summer monsoon (ASM). However, knowledge of several monsoon features and the underlying physical processes are still inadequate, because of which the modeling and long-range forecast of ASM remain elusive. Distribution of clouds over the Indian subcontinent and the surrounding regions during ASM (JuneSeptember period) has several important features. For example, the highest cloud top altitudes (Meenu et al., 2010) and integrated latent heat release (Zuluaga et al., 2010) over the planet occur over the Bay of Bengal (BoB) during ASM. In contrast to the near-cancellation of the longwave and shortwave cloud radiative forcing at the top-of-atmosphere over the tropics, net cloud radiative forcing over a vast region in the Indian subcontinent and the surrounding oceans is negative during ASM (Rajeevan and Srinivasan, 2000; Roca et al., 2005). Using long-term spaceborne observations of cloud characteristics over south Asia and the adjoining oceanic regions, this paper brings out the occurrence, characteristics and potential genesis mechanism of a "pool of inhibited cloudiness" covering an area of more than 1 million $\mathrm{km}^{2}$ over the south BoB during the ASM. Though the existence of this feature is seen in the regional distributions of clouds, precipitation and outgoing longwave radiation (OLR) reported in the literature (e.g., Goswami et al., 1999; Meenu et al., 2007, 2010), the contribution of low-, middle- and high-level clouds in its manifestation could not be deciphered unambigously. This is primarily because of the limitation of spaceborne passive radiometric observations, which are generally biased towards high-altitude clouds due to the absorption of

Published by Copernicus Publications on behalf of the European Geosciences Union. 

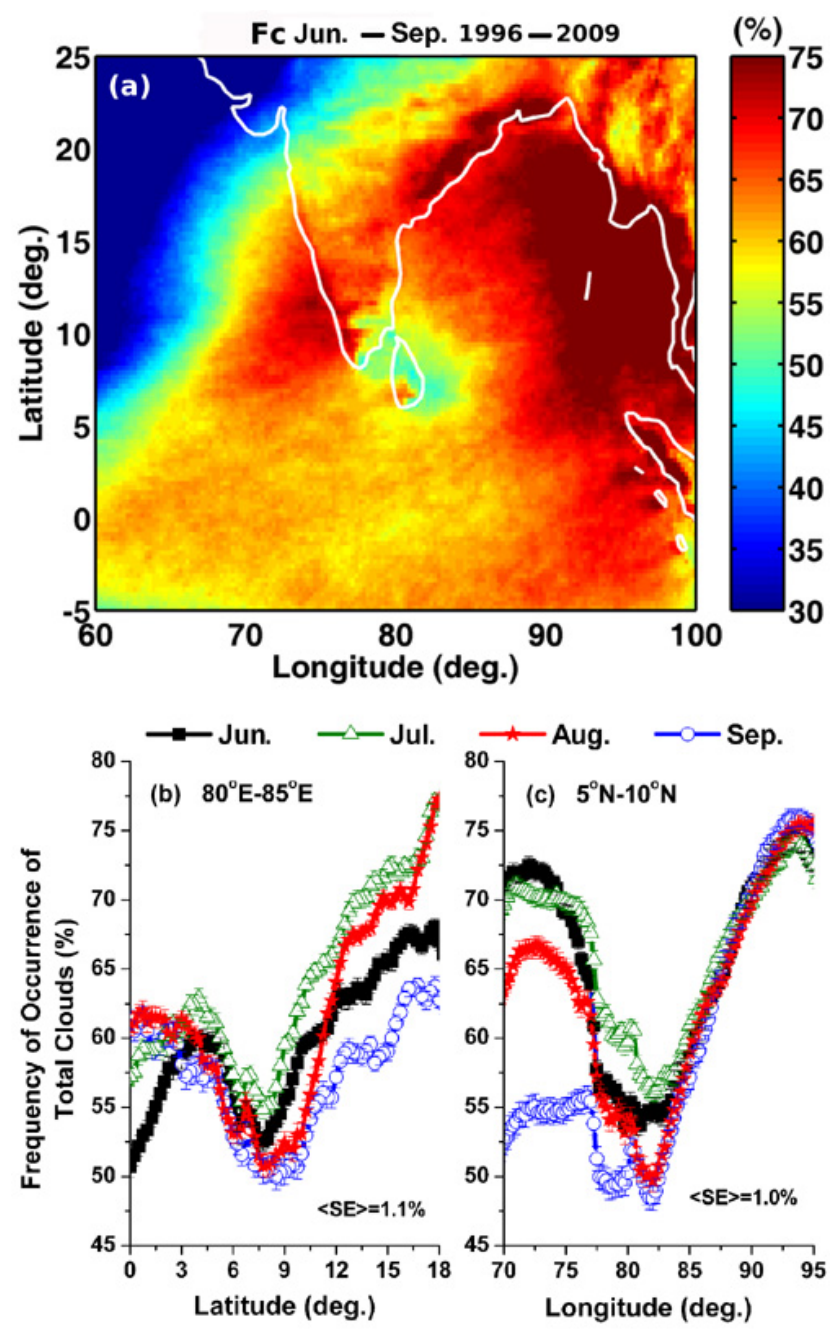

Fig. 1. (a) Long-term (1996-2009) seasonal mean spatial distribution of the frequency of occurrence of clouds $\left(F_{\mathrm{c}}\right.$, expressed in percentage) observed during ASM. (b) Long-term monthly mean latitudinal variations of the frequency of occurrence of clouds, averaged along in $80-85^{\circ}$ E during June, July, August and September. (c) Same as (b) but for the longitudinal variation averaged along $5-10^{\circ} \mathrm{N}$. The vertical lines indicate the standard errors of $F_{\mathrm{c}}$ and $<\mathrm{SE}>$ represents average error.

radiation emitted from lower cloud layers by the cloud layer above them. In contrast to this, the active remote sensing of hydrometeors using CloudSat have enabled the detection of clouds occurring below optically thick high-altitude clouds (Haynes and Stephens, 2007), which elucidate certain unique features of their vertical distribution in the "pool". Potential mechanisms for the genesis of the "pool" are identified by analysing the sea surface temperature (SST), atmospheric circulation and spaceborne observations of surface wind divergence.

\section{Data}

Spatial distribution of clouds during 1996-2009 is derived on a daily basis by analyzing the data obtained from the Advanced Very High Resolution Radiometer (AVHRR; Global Area Coverage - GAC) onboard NOAA-14/16/18 satellites. This data has daily coverage over the entire study region considered here. Pixel resolution of AVHRR-GAC data is $4 \mathrm{~km}$ at nadir. Brightness temperature observed in the thermal infrared bands are used to identify the cloudy pixels based on the method described in Meenu et al. (2010). Pixel-level cloudiness derived from each satellite pass is transformed into a uniform geographical grid of size $0.25^{\circ}$. The monthly mean frequency of occurrence of clouds $\left(F_{\mathrm{c}}\right)$ in each grid is obtained by averaging the observed daily mean cloudiness in the respective grids for each month. Entire AVHRR data during the 1996-2009 period is used in this analysis.

Vertical distribution of clouds are obtained from the polar orbiting sun-synchronous satellite, CloudSat, having a Cloud Profiling Radar (CPR) operating at $94 \mathrm{GHz}$, which provides the altitude profiles of backscattered radar signal from hydrometeors with a vertical resolution of $240 \mathrm{~m}$ along the subsatellite track (Haynes and Stephens, 2007). The footprint size of a single profile is $1.7 \mathrm{~km}$ along track by $1.4 \mathrm{~km}$ across track. The CloudSat orbits have a repetivity of 16 days. The raw data is processed at the CloudSat data processing centre to derive different science data products. This study utilizes the cloud geometrical profile product, 2B-GEOPROF (Version-4) which provides the cloud mask containing the information on cloud layers and their top and base altitudes for the individual profiles along the satellite orbit (Mace et al., 2007). This data are used to estimate the monthly and seasonal mean altitude profiles of the frequency of occurrence of clouds $\left(F_{\mathrm{ALT}}\right)$ and their zonal and meridional distributions during the June-September period of 2006-2009.

Long-term seasonal mean spatial distribution of precipitation over the study domain are obtained from the Global Precipittion Climatology Project (GPCP Version 2.1) data (Adler et al., 2003), which has a geographical resolution of $2.5^{\circ}$. Long term (1996-2009) monthly and seasonal mean values of SST are examined using the NOAA optimum interpolated SST (OI-SST). The surface wind divergence (SWD) during this period are obtained from the spaceborne scatterometer observations (European Remote Sensing Satellite - ERS 1 and 2, and QuikScat satellite of NASA), which have a spatial resolution of $0.5^{\circ}$ (QuikScat) and $1^{\circ}$ (ERS) (Liu, 2002). The atmospheric circulation data during the above period are obtained from ECMWF ERA-Interim reanalysis.

\section{Results and discussion}

Figure 1a shows the long-term (1996-2009) seasonal mean distribution of $F_{\mathrm{c}}$ over the Indian subcontinent and the surrounding oceanic regions during ASM derived from AVHRR 


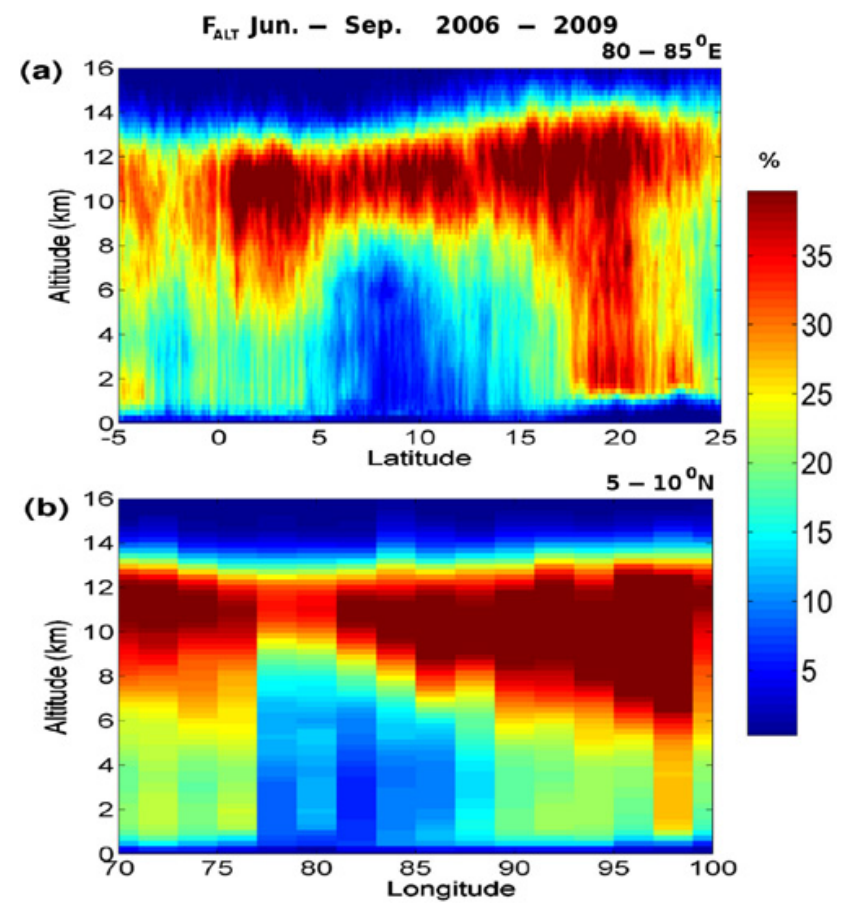

Fig. 2. (a) Four-year (2006-2009) average seaonal mean latitudealtitude cross section of the frequency of occurrence of clouds ( $F_{\mathrm{ALT}}$, expressed in percentage) during ASM along $80-85^{\circ} \mathrm{E}$. (b) Same as (a) but for the longitude-altitude cross section averaged along $5-10^{\circ} \mathrm{N}$.

data, which clearly shows the presence of a large "pool of inhibited cloudness" over the southwest BoB centred around $8^{\circ} \mathrm{N}, 82^{\circ} \mathrm{E}$ adjoining Sri Lanka. Seasonal mean values of $F_{\mathrm{c}}$ in the "pool" are $<50 \%$ while those over the surrounding regions are $\sim 70-90 \%$. The corresponding long-term monthly mean latitude and longitude variations of $F_{\mathrm{c}}$ averaged along $80-85^{\circ} \mathrm{E}$ and $5-10^{\circ} \mathrm{N}$, respectively, during June, July, August and September are depicted in Fig. 1b, c, which show the persistence of the "pool" throughout the ASM, though its prominence is maximum during July-August. Similar features are also seen in the regional distribution of clouds reported by Meenu et al. (2007, 2010). As identified from the well shaped latitudinal and longitudinal variations of $F_{\mathrm{c}}$ (Fig. 1b, c), the "pool" extends from 77 to $90^{\circ} \mathrm{E}$ and 3 to $13^{\circ} \mathrm{N}$, which are remarkably similar during all the above months. Though not depicted here, this "pool" is also clearly observable in the monthly and seasonal mean images of the outgoing longwave radiation (with an enhancement of $\sim 10$ to $25 \mathrm{~W} \mathrm{~m}^{-2}$ over the pool compared to its surroundings) and is manifested by remarkably less precipitation. Such a "pool" is absent during other seasons.

The seasonal mean latitude-altitude cross section of $F_{\text {ALT }}$ during the ASM of 2006-2009 derived from 2B-GEOPROF, averaged along the $80-85^{\circ} \mathrm{E}$ longitude band is shown in Fig. 2a. The corresponding longitude-altitude cross section

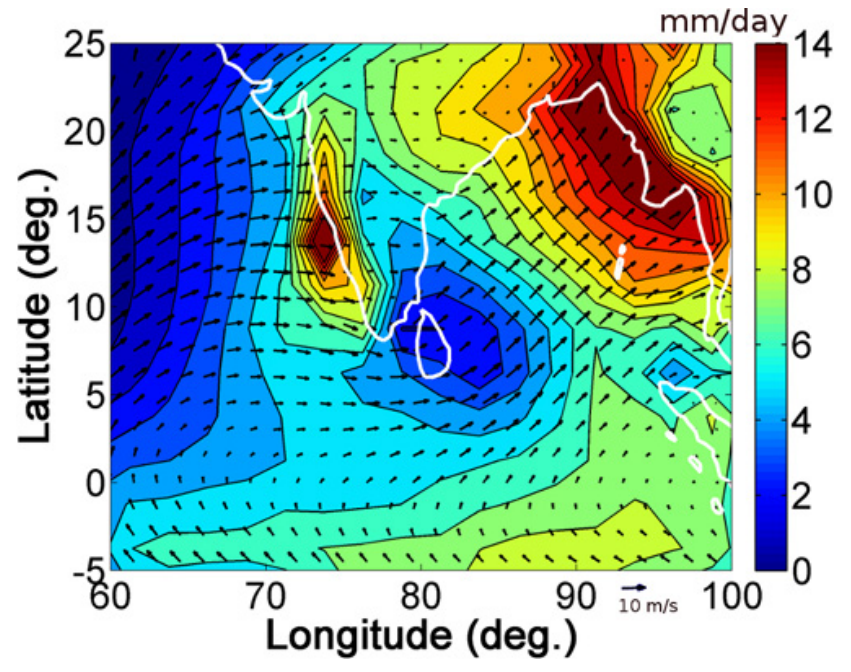

Fig. 3. Long-term (1996-2009) seasonal mean regional distribution of precipitation rate $\left(\mathrm{mm} \mathrm{day}^{-1}\right)$ during ASM. The vectors represent the corresponding long-term seasonal mean winds at $1000 \mathrm{hpa}$ level during this season.

of $F_{\text {ALT }}$ averaged for the $5-10^{\circ} \mathrm{N}$ latitude band is depicted in Fig. 2b. The most remarkable feature observed in Fig. 2a, b is the drastic decrease or near-absence of clouds in the lower and middle troposhere in the "pool" region, which appears as a vault whose location and boundaries match with those derived from Fig. 1. (It may be stated here that the features of cloud distribution, including characteristics of the "pool" region, observed using AVHRR data during 20062009 are similar to that for 1996-2009 shown in Fig. 1). The value of $F_{\mathrm{ALT}}$ below $\sim 7 \mathrm{~km}$ at the centre of the "pool" is generally $<10 \%$, which is markedly lower than that over the surrounding regions $\left(F_{\mathrm{ALT}} \sim 25-35 \%\right)$ where the deep convective clouds are present from $<1 \mathrm{~km}$ and extend up to $\sim 13 \mathrm{~km}$. However, $F_{\mathrm{ALT}}$ increases considerably above $\sim 7 \mathrm{~km}$ and its spatial gradient almost vanishes in the altitude band of $\sim 10-13 \mathrm{~km}$ where $F_{\mathrm{ALT}}$ is $>40 \%$ over a vast region. This might be the reason for the absence of the pool of inhibited cloudiness in the regional distribution of semitransparent cirrus clouds reported by Sunilkumar et al. (2010). Similar to $F_{\mathrm{c}}$, the considerably less value of $F_{\text {ALT }}$ observed below $\sim 7 \mathrm{~km}$ in the "pool" is most prominent in July-August. Most of the high-altitude clouds observed over the "pool" region might be cirrus clouds generated by westward spreading of outflows from the deep convective systems situated at the eastern BoB by the strong upper tropospheric easterly winds, which is a characteristic feature of ASM (e.g., Sathiyamoorthy et al., 2004).

Since the "pool" is characterized by weak occurrence or near-absence of low- and middle-level clouds, it might be manifested in precipitation as well. This is shown in Fig. 3, which depicts the long-term (1996-2009) seasonal mean precipitation rate (in $\mathrm{mm} \mathrm{day}^{-1}$ ) over the study area during 


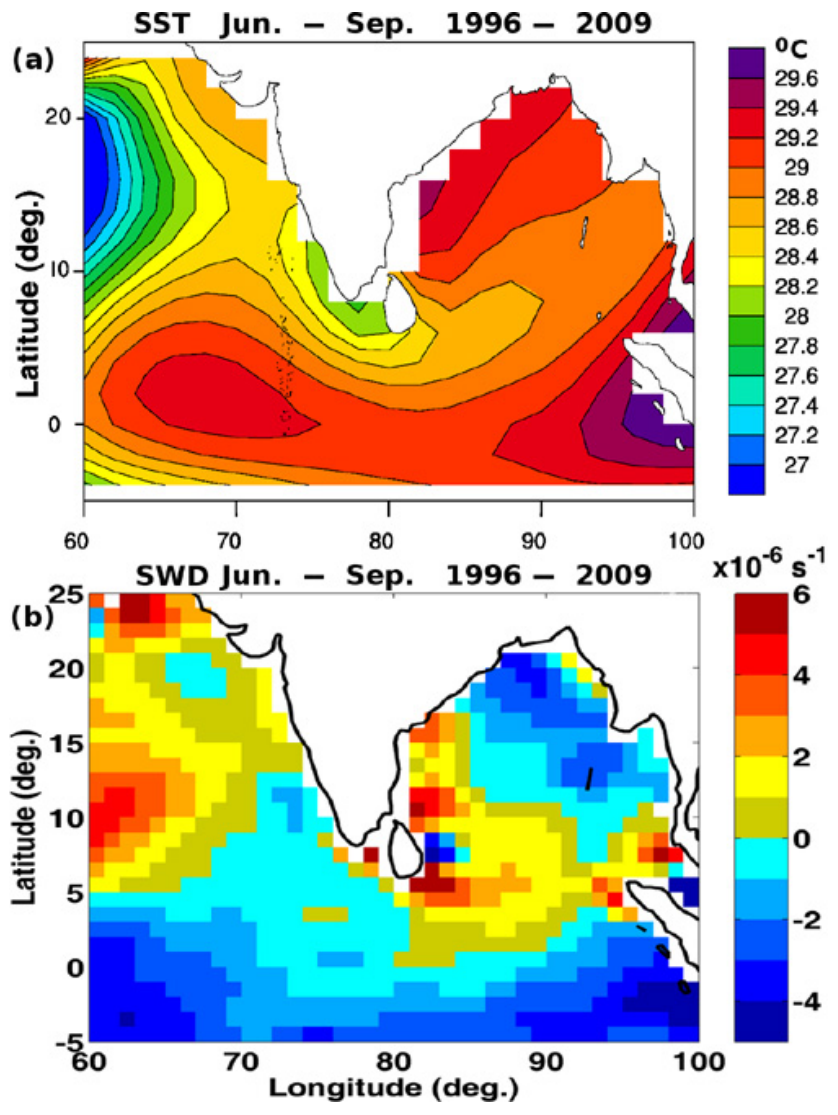

Fig. 4. Long-term (1996-2009) seasonal mean distribution of (a) SST and (b) surface wind divergence $\left(\mathrm{s}^{-1}\right)$ during ASM.

ASM, obtained from the GPCP data. Long-term seasonal mean winds at 1000 hpa level obtained from ECMWF-ERA are also shown in this figure. Precipitation rate over the "pool" region is substantially less (seasonal mean precipitation rate of $<3 \mathrm{~mm} \mathrm{day}^{-1}$ ) compared to the surrounding regions of deep convection, especially over the east Arabian Sea and north Bay of Bengal where the precipitation rates are in the range of $8-14 \mathrm{~mm} \mathrm{day}^{-1}$. The precipitation rates over the east and central equatorial Indian Ocean are also quite large $\left(>6 \mathrm{~mm} \mathrm{day}^{-1}\right)$. As inferred from the vector winds at $1000 \mathrm{hpa}$ level, the large-scale convection and precipitation at the Bay of Bengal and east Arabian Sea might have been caused by strong convergence of surface wind, aided by orographic lifting.

Role of SST on the genesis of the "pool" is examined using the long-term (1996-2009) seasonal mean spatial distribution of SST depicted in Fig. 4a. It shows a cold tongue originating off the southern tip of India (STI) and extending up to the south central BoB. This cold tongue (Joseph et al., 2005) arises from the ocean upwelling caused by the prevailing surface wind and its eastward spreading by the summer monsoon current into the BoB (Rao et al., 2006). However, the cold tongue has significantly large eastward extension than the "pool", while the latter extends farther to the north compared to the former. The locations of minima in SST and cloudiness are also different: $F_{\mathrm{c}}$ at the west coast of Sri Lanka is significantly larger than that at the east, though SST at the former region is $\sim 1{ }^{\circ} \mathrm{C}$ lesser than that at the latter. Furthermore, SST is $\geq 28.4{ }^{\circ} \mathrm{C}$ at most part of the "pool", which is sufficiently high for the development of convection and clouds (e.g., Gadgil et al., 1984). Figure $4 \mathrm{~b}$ shows the long-term seasonal mean surface wind divergence observed using spaceborne scatterometers during ASM. In general, the surface wind is significantly diverging at the "pool" and converging outside this region. Over the "pool" region, this would produce a moisture divergence at the surface and subsidence from above, which would inhibit the cloud formation. Closure of the above surface wind field suggests the existence of a regional scale atmospheric circulation cell with subsidence at the "pool" and convection at its surroundings. This inference is well supported by the horizontal and vertical distribution of clouds depicted in Figs. 1 and 2. This mini-circulation might be the potential mechanism for the inhibition of cloudiness and precipitation at the "pool".

Evidence for such a mini-circulation is examined using ERA data. Figure 5 depicts the latitudinal and longitudinal cross sections of the altitude profiles of long-term seasonal mean vertical wind (in $\mathrm{Pa} \mathrm{s}^{-1}$ ), sliced through the centre of the "pool", which shows a strong subsidence below $\sim 700 \mathrm{hPa}(\sim 3 \mathrm{~km})$ at/near the "pool" region and convection at its surroundings. However, the spatial distribution of the subsidence and convection are not well matched with that inferred from Figs. 1-4: note that the cloud-free region extends up to $\sim 7 \mathrm{~km}$ and up to the east BoB, while the downdraft seen in Fig. 5 is significantly limited in altitude and its eastward extent. This shows that the actual structure and magnitude of the mini-circulation might have been underestimated by the reanalysis data.

The above mini-circulation cell, embedded in the synoptic-scale monsoon circulation and responsible for the genesis of the "pool", might be triggered by the considerable spatial gradient of latent heating $(\mathrm{LH})$ in the troposphere over the geographically fixed zones of large-scale cloudiness and precipitation at the east and equatorial Indian Ocean, north and east BoB, southeast Arabian Sea and Indian land-mass, as a result of the modulation of summer monsoon circulation by SST, orography and land-sea contrast. The largest monthly mean values of LH over the above deep convective regions (though having considerable spatio-temporal variations) occur between $3-7 \mathrm{~km}$ altitude where it is typically in the range of 1.4 to $4.0 \mathrm{~K} \mathrm{day}^{-1}$, while the corresponding values of LH over the "pool" are negligible (Zuluaga et al., 2010). Whereas the synoptic-scale monsoon circulation provides the main closure mechanism for the updraft at the fixed zones of deep convection, this study shows that the mini-circulation described above also contributes significantly to the maintenance of large-scale convection at the 

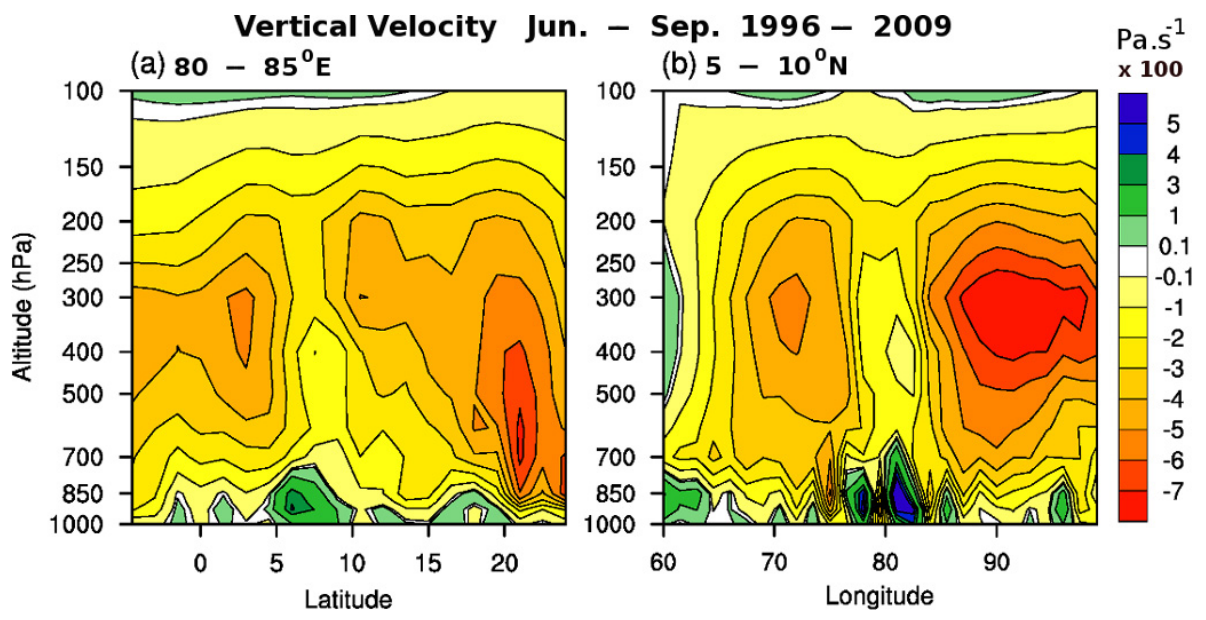

Fig. 5. (a) Long-term (1996-2009) seaonal mean latitude-altitude cross section of the pressure vertical velocity $\left(\mathrm{Pas}^{-1} \times 100\right)$ averaged along $80-85^{\circ}$ E, obtained from ERA. (b) Same as (a) but for the longitude-altitude cross section averaged along $5-10^{\circ} \mathrm{N}$. The vertical velocities are multiplied by 100 in the above figures for better visualisation.

above zones and hence would be an important component of the ASM. However, the strength of the "pool" and the mini-circulation might be modulated by the active and break spells of the monsoon (or vice versa), which is not investigated here. Notwithstanding the larger solar heating of the surface due to less cloudiness, the "pool" region is able to maintain low SST compared to the largely cloudy regions at its surroundings. This shows that, in addition to the contribution from the spreading of cold waters from STI (Rao et al., 2006), the cold SST at the "pool" might also be driven by the ocean upwelling caused by the surface wind divergence associated with the mini-circulation described above (Fig. 4b).

\section{Conclusions}

Using long-term satellite observations of clouds, this study clearly shows the persistence of a "pool of inhibited cloudiness" over the southwest Bay of Bengal throughout the Asian summer monsoon season. Frequency of occurrence of clouds in this "pool" is $20-40 \%$ less than the surroundings. Seasonal mean precipitation rate over the "pool" is $<3 \mathrm{~mm} \mathrm{day}^{-1}$ while that over the surrounding regions is mostly in the range of 6-14 mm day ${ }^{-1}$. Though this "pool" is observed in the regional distributions of clouds, precipitation, and OLR reported earlier, the contribution of low-, middle- and high-level clouds in its manifestation could not be deciphered unambigously. This information is essential for identifying the genesis of the "pool". This study, based on the vertical distribution of clouds observed using CloudSat, reveals that the "pool" is almost completely contributed by a drastic reduction or near-absence of clouds below $\sim 7 \mathrm{~km}$ that appear as a vault-like structure in the zonal and meridional cross section of the vertical distribution of clouds. In contrast, spatial gradient of high-altitude clouds over the entire region is negligible. The geographical location of this pool is remarkably consistent during the JuneSeptember period and occurs between $77-90^{\circ} \mathrm{E}$ in longitude and $3-13^{\circ} \mathrm{N}$ in latitude, which is surrounded by regions having large-scale convective clouds. This study shows that the physical mechanism for the genesis of the "pool" might, most likely, stem from the existence of a mini-circulation in the lower troposphere with significant divergence of surface wind at the "pool" and subsidence above, which is closed by the surface wind convergence and updraft in the troposphere over the surrounding deep convective regions. This minicirculation is embedded in the large-scale monsoon circulation and might be a dynamical response of the atmosphere to the considerable spatial gradient of latent heating caused by the geographically fixed convective regions surrounding the "pool". The subsidence and surface wind divergence of air at the "pool" will be at least partly responsible for closure of the strong updraft at the surrounding deep convective regions and hence might be an important component of the ASM. Genesis and maintenance of the "pool" might be further influenced by orography of the region, the low-level jet and the relatively low SST at the south BoB. It is also likely that, at least part of the reduction in SST observed in the "pool" is contributed by the surface wind divergence. However, significant differences exist in the mini-circulation features derived from the reanalysis of atmospheric circulation and that inferred from the spaceborne observations of surface wind divergence and cloud distribution. The observed minicirculation might play an important role in the monsoon dynamics as well as in the active-break spells of ASM, which needs to be explored further.

Acknowledgements. CloudSat 2BGeoProf data was obtained from http://cloudsat.cira.colostate.edu. AVHRR data was obtained from http://www.class.noaa.gov. ERA-40 data was provided by 
ECMWF. NOAA OI-SST was obtained from NOAA-CIRES Climate Diagnostics Center, Boulder, Colorado. The ERS-1/2 and QuikSCAT scatterometer data were taken from CERSAT, at IFREMER, Plouzané (France). The GPCP combined precipitation data were developed and computed by the NASA/Goddard Space Flight Center's Laboratory for Atmospheres as a contribution to the GEWEX Global Precipitation Climatology Project. A. K. M. Nair and S. Meenu are supported by ISRO through Research Fellowship and Research Associateship respectively.

Topical Editor P. Drobinski thanks one anonymous referee for her/his help in evaluating this paper.

\section{References}

Adler, R. F., Huffman, G. J., Chang, A., Ferraro, R., Xie, P. P., Janowiak, J., Rudolf, B., Schneider, U., Curtis, S., Bolvin, D., Gruber, A., Susskind, J., Arkin, P., and Nelkin, E.: The Version-2 Global Precipitation Climatology Project (GPCP) monthly precipitation analysis (1979-present), J. Hydrometeor., 4, 11471167, 2003.

Gadgil, S., Joseph, P. V., and Joshi, N. V.: Ocean-atmosphere coupling over monsoon regions, Nature, 312, 141-143, 1984.

Goswami, B. N., Krishnamurthy, V., and Annamali, H.: A broadscale circulation index for the interannual variability of the Indian summer monsoon, Q. J. Roy. Meteorol. Soc., 125, 611-633, 1999.

Haynes, J. M. and Stephens, G. L.: Tropical oceanic cloudiness and the incidence of precipitation: Early results from CloudSat, Geophys. Res. Lett., 34, L09811, doi:10.1029/2007GL029335, 2007.

Joseph, P. V., Sooraj, K. P., Babu, C. A., and Sabin, T. P.: A cold pool in the Bay of Bengal and its interaction with the activebreak cycle of the monsoon, CLIVAR Exchanges 34, Southampton, UK, 10 10-12, 2005.

Liu, W. T.: Progress in scatterometer application, J. Oceanogr., 58, 121-136, 2002.
Mace, G. G., Marchand, R., Zhang, Q., and Stephens, G.: Global hydrometeor occurrence as observed by CloudSat: Initial observations from summer 2006, Geophys. Res. Lett., 34, L09808, doi:10.1029/2006GL029017, 2007.

Meenu, S., Rajeev, K., Parameswaran, K., and Raju, C. S.: Characteristics of double ITCZ over the tropical Indian Ocean, J. Geophys. Res., 112, D11106, doi:10.1029/2006JD007950, 2007.

Meenu, S., Rajeev, K., Parameswaran, K., and Nair, A. K. M.: Regional distribution of deep clouds and cloud top altitudes over the Indian subcontinent and the surrounding oceans, J. Geophys. Res., 115, D05205, doi:10.1029/2009JD011802, 2010.

Rajeevan, M. and Srinivasan, J.: Net cloud radiative forcing at the top of the atmosphere in the Asian monsoon region, J. Climate, 13, 650-657, 2000.

Rao, R. R, Kumar, M. S. G., Ravichandran, M., Samala, B. K., and Anitha, G.: Observed intra-seasonal variability of mini-cold pool off the southern tip of India and its intrusion into the south central Bay of Bengal during summer monsoon season, Geophys. Res. Lett., 33, L15606, doi:10.1029/2006GL026086, 2006.

Roca, R., Louvet, S., Picon, L., and Desbois, M.: A study of convective systems, water vapor and top of the atmosphere cloud radiative forcing over the Indian Ocean using INSAT-1B and ERBE data, Meteorol. Atmos. Phys., 90, 49-65, doi:10.1007/s00703004-0098-3, 2005.

Sathiyamoorthy, V., Pal, P. K., and Joshi, P. C.: Influence of the upper-tropospheric wind shear upon cloud radiative forcing in the Asian monsoon region, J. Climate, 17, 2725-2735, 2004.

Sunilkumar, S. V., Parameswaran, K., Rajeev, K., Krishna Murthy, B. V., Meenu, S., Mehta, Sk. K., and Babu, A.: Semitransparent cirrus clouds in the Tropical Tropopause Layer during two contrasting seasons, J. Atmos. Solar Terr. Phys. 72, 745-762, doi:10.1016/j.jastp.2010.03.020, 2010.

Zuluaga, M. D., Hoyos, C. D., and Webster, P. J.: Spatial and temporal distribution of latent heating in the south Asian monsoon region, J. Climate, 23, 2010-2029, doi:10.1175/2009JCLI3026.1, 2010. 